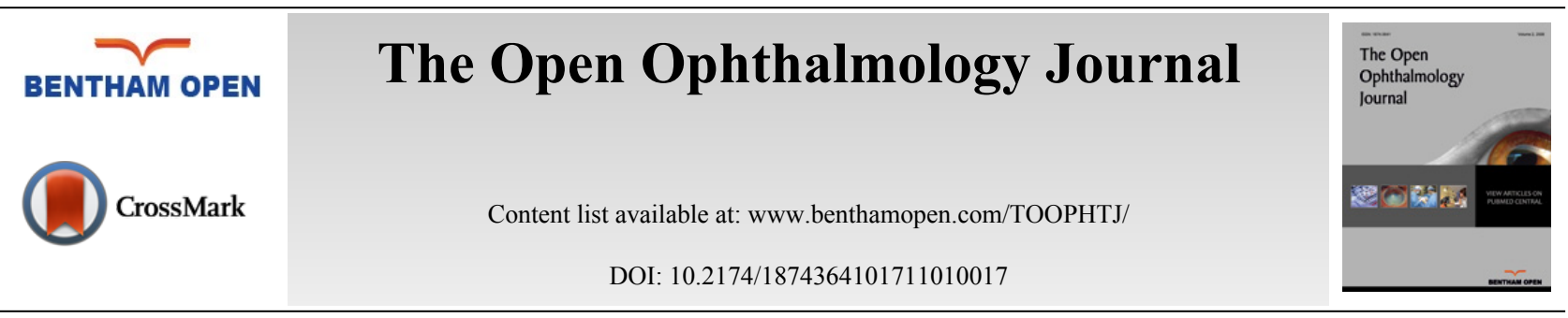

RESEARCH ARTICLE

\title{
Macular Evaluation with Spectral Domain Type Optic Coherence Tomography in Eyes with Acute Nonarteritic Ischemic Optic Neuropathy at the Presentation Visit
}

\author{
Oya Donmez, Gamze Kocaoglu, Aylin Yaman, Meltem Soylev Bajin and Ali Osman Saatci* \\ Department of Ophthalmology, Dokuz Eylul University, Izmir, Turkey
}

Received: August 08, 2016

Revised: December 09, 2016

Accepted: January 13, 2017

\begin{abstract}
:
Purpose:

To evaluate the macula with spectral domain type optic coherence tomography (OCT) in eyes with acute nonarteritic anterior ischemic optic neuropathy (NAION) at the presentation visit.
\end{abstract}

\section{Methods:}

Medical charts of the 133 patients who received the diagnosis of acute NAION between January 2008 and July 2014 at the Neuroophthalmology unit of Dokuz Eylul University were reviewed retrospectively. Sixtythree patients within 30 days of symptom onset with available baseline spectral domain type macular OCT were included in this study. Clinical and macular characteristics of the affected eye were assessed and compared to the fellow eyes.

\section{Results:}

Sixty-three eyes of 63 patients comprised the study group. Twenty one study eyes (33.3\%) had normal posterior pole, 22 (34.9\%) some evidence of subretinal fluid, $10(15.8 \%)$ vitreomacular adhesion, five (7\%) age-related macular degeneration related changes, four $(6 \%)$ epiretinal membrane and one (1\%) previous grid laser scars. On the other hand, 41 of 63 the fellow eyes $(65 \%)$ had normal posterior pole, ten (15.8\%), vitreomacular adhesion, seven (10.7\%), age-related macular degeneration related changes, three (4\%) epiretinal membrane and two (3\%) other type of changes. OCT scan passing through the fovea exhibited 10 or more hyperreflective dots in $10(15 \%)$ of the study eyes whereas two of the fellow eyes $(3.2 \%)$ had 10 or more hyperreflective dots.

\section{Conclusion:}

Macular OCT can be a part of the routine neuroophthalmologic examination in patients with acute NAION not only to show the NAION related changes such as the subretinal fluid accumulation but also to identify the other coexistent macular abnormalities.

Keywords: Anti-VEGF agents, Macula, Nonarteritic ischemic optic neuropathy, Optic coherence tomography, Ranibizumab, Triamcinolone.

\section{INTRODUCTION}

Acute nonarteritic anterior ischemic optic neuropathy (NAION) is the most common optic neuropathy at the elderly population presenting with painless unilateral sudden visual loss [1].

As expected, retinal nerve fiber layer changes may ensue and were previously demonstrated in eyes with acute NAION with various optic coherence tomography (OCT) devices [2 - 4]. Despite the fact that macular changes may be a likely contributor to the visual loss macular changes were relatively less studied with spectral domain type OCT [5 7].

* Address correspondence to this authors at the Mustafa Kemal Sahil Bulvari, No: 73, A Blok D: 9, 35320 Narlidere/Izmir, Turkey; Tel: +90 532 7437071; E-mail: osman.saatci@yahoo.com 
We hereby assessed the macular changes tomographically in 63 eyes of 63 patients with acute NAION who were examined within a month of symptom onset.

\section{SUBJECTS AND METHODS}

This study was approved by the Dokuz Eylul University Institutional Review Board (1496-GOA). Medical charts of the 133 patients who received the diagnosis of acute NAION at the Neuro-ophthalmology unit of Dokuz Eylul University were reviewed between January 2008 and July 2014 retrospectively.

The diagnosis was based on the criteria set for the ischemic optic neuropathy decompression trial (presence of visual disturbances, relative afferent pupillary defect, a swollen disc and an appropiate visual field defect.) [8]. Complete blood cell count, erythocyte sedimentation rate and C-reactive protein analysis were obtanined to exclude the arteritic type of anterior ischemic optic neuropathy. Sixtythree eyes of 63 patients within 30 days of symptom onset with available baseline macular OCT scans were included in this study. Patients who had experienced an episode of acute NAION in the fellow eye were excluded. Besides routine eye examination each fundus was evaluated by indirect ophthalmoscopy, contact lens biomicroscopy and optic coherence tomography. Additional ocular and/or systemic tests were performed to rule out other ocular and systemic diseases where deemed appropiate. Demographic data, coexistent systemic diseases and ocular findings were noted. Macular OCT using a cross type scan was obtained with the spectral domain type optic coherence tomography (Heidelberg Spectralis HRA/OCT) in all eyes. Subretinal fluid detected in the OCT sections was assumed subfoveal if it was just located under the center of the fovea. Subretinal fluid located at other locations was also taken into consideration. Hyperreflective dots were defined as the presence of focal hyperreflective material scattered in outer and inner retinal layers in at least one scan passing through the fovea and the OCT scan harboring the most hyperreflective dots in number was taken into consideration for quantification. Hyperreflective dots were classified on the basis of quantity (Few if less than 10; significantly present if more than 10) (Adapted from Coscas et al.) [9]. Two blinded ophthalmologist counted the hyperreflective dots and the mean was taken into account.

The independent and paired t tests were used for statistical analysis and 0.05 was determined as cut of $p$ value.

\section{RESULTS}

Sixtythree eyes of 63 patients were included in the study. Thirtynine patients were male and 24 , woman. The mean age was $60.82 \pm 10.2$ years (Range, $42-90$ years). The most common comorbidity was hypertension $(50.8 \%) .38 .1 \%$ of patients had diabetes mellitus and $22.2 \%$ of them had both diabetes mellitus and hypertension. The time between visual loss and the presentation varied between 1-30 days (Mean 11.8 days). At the presentation mean-best corrected visual acuity (BCVA) was $1.12 \pm 0.86 \log$ MAR (Range 0.00-3.10) and mean central macular thickness (CMT) was 260.4 \pm $59.9 \mu \mathrm{m}$ in the study eyes (range $178-435 \mu \mathrm{m}$ ). BCVA in the fellow eyes was $0.29 \pm 0.53 \log$ MAR (range $0.00-3.10$ ) and CMT 225.3 $\pm 27.5 \mu \mathrm{m}$ (Range, 155-331 $\mu \mathrm{m}$ ). Mean BCVA was poorer and mean CMT was thicker in the study eyes statistically $(\mathrm{p}=0.000$ and $\mathrm{p}=0.000)$.

Twenty one study eyes (33.3\%) had normal posterior pole, 22 (34.9\%) some evidence of subretinal fluid (Six eyes with subretinal fluid in the papillomacular area, five with subfoveal subretinal fluid, five with subfoveal subretinal fluid + subretinal fluid in the papillomacular area, three with subfoveal subretinal fluid + intraretinal fluid + subretinal fluid in the papillomacular area, one with subretinal fluid in papillomacular area + macular RPE atrophy, one with subfoveal subretinal fluid + subretinal fluid in papillomacular area + intraretinal fluid + epiretinal membrane and one with subfoveal subretinal fluid + subretinal fluid in papillomacular area + hard exudates), 10 (15.8\%) vitreomacular adhesion, five (7\%) age-related macular degeneration related changes, four (6\%) epiretinal membrane and one (1\%) previous grid laser scars.

On the other hand, 41 of 63 fellow eyes (65\%) had normal posterior pole, ten $(15.8 \%)$ vitreomacular adhesion, seven $(10.7 \%)$ age-related macular degeneration related changes, three $(4 \%)$ epiretinal membrane and two $(3 \%)$ other type of changes. OCT scan passing through the foveola exhibited 10 or more hyperreflective dots in 10 (15\%) of the study eyes whereas two of the fellow eyes $(3.2 \%)$ had 10 or more hyperreflective dots.

Table 1. Macular findings of the study and fellow eyes.

\begin{tabular}{|l|c|c|c|}
\hline & Study Eyes & Fellow Eyes & p value \\
\hline Normal posterior pole & $21(33.3 \%)$ & $41(65 \%)$ & $0.00 *$ \\
\hline Presence of subretinal fluid & $22(34.9 \%)$ & $1(1 \%)$ & 1.00 \\
\hline
\end{tabular}




\begin{tabular}{l} 
(Table $\llbracket$ ) contd..... \\
\hline
\end{tabular}

(Ten or more numbers)

* $\mathrm{p}<0.05$

**Eyes with hyperreflective dots overlap with other OCT findings

Macular findings of the study and fellow eyes with the OCT were summarized in Table 1. Examples of OCT scans demonstrating the various macular changes observed in the study group are seen in Figs. (1-5).

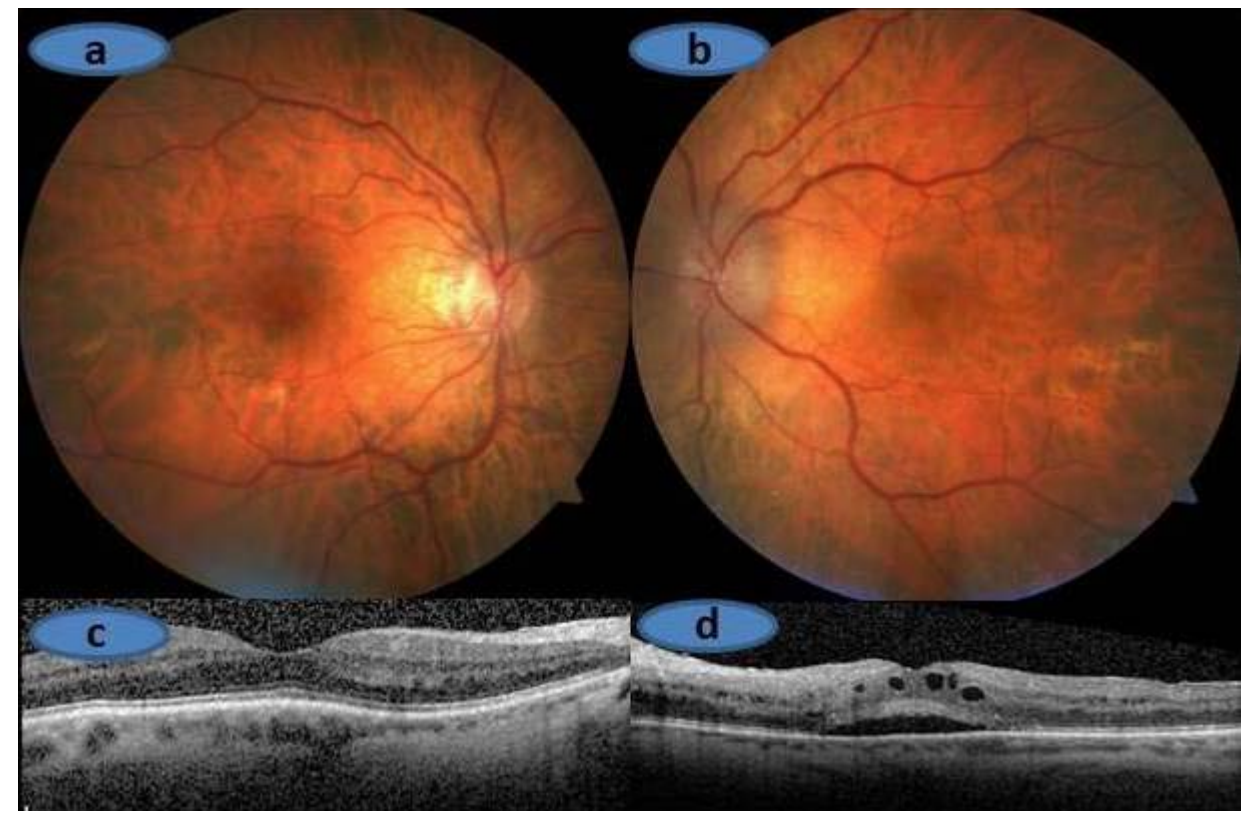

Fig. (1). (A) and (C). Right Eye, Normal optic disc with normal macula scan. (B) and (D). Left eye, Swollen optic disc and subfoveal subretinal + intraretinal fluid on the OCT scan.

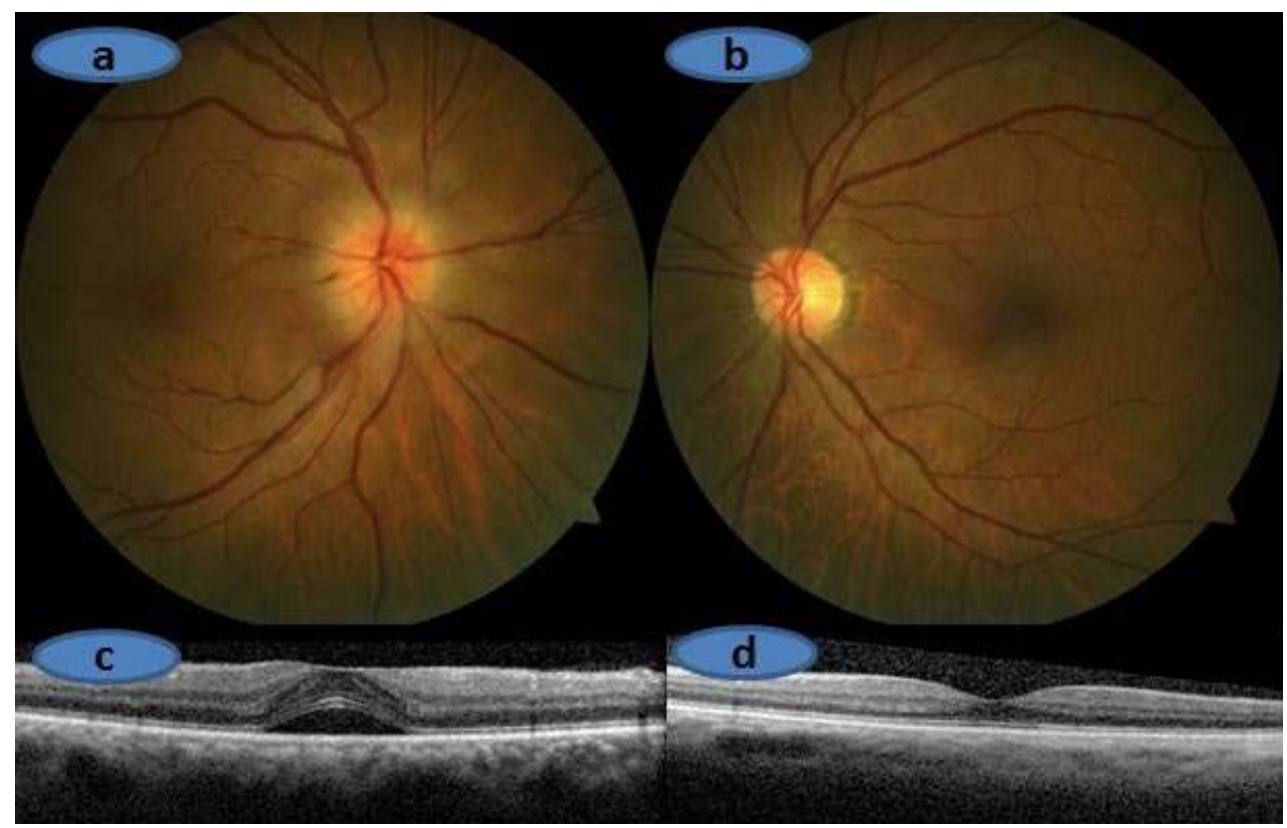

Fig. (2). (A) and (C). Right Eye, Swollen optic disc and subfoveal subretinal fluid on the OCT scan. (B) and (D). Left Eye, Normal optic disc with normal macula scan. 


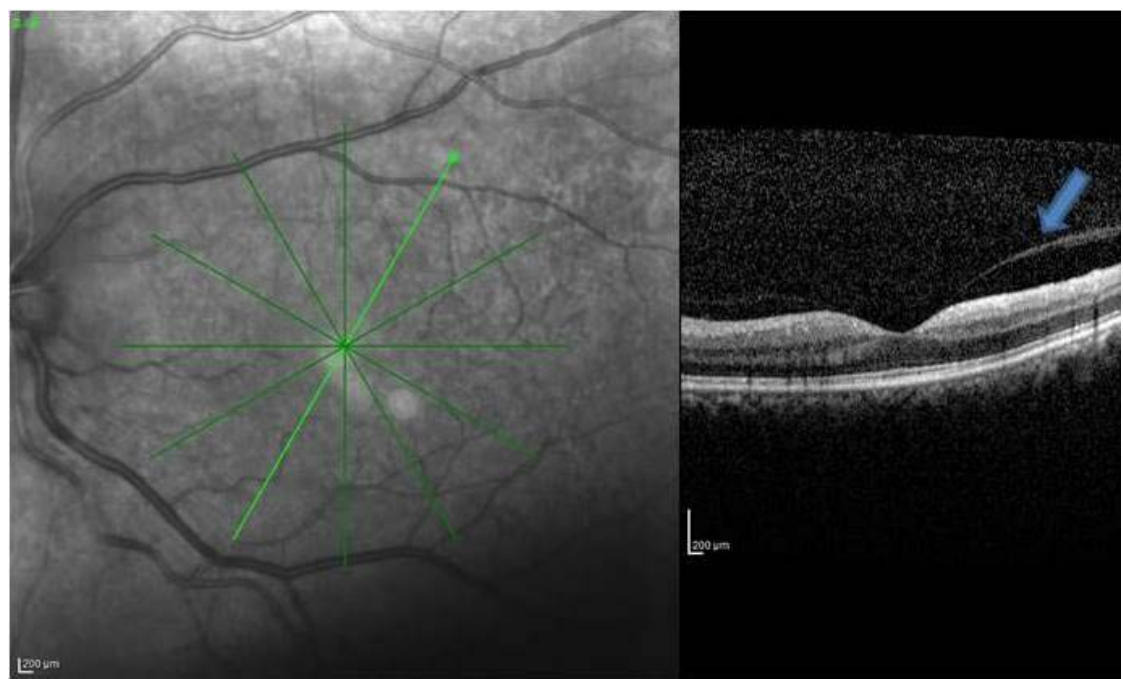

Fig. (3). Left eye, Swollen optic disc and vitreomacular adhesion to the fovea (arrow).

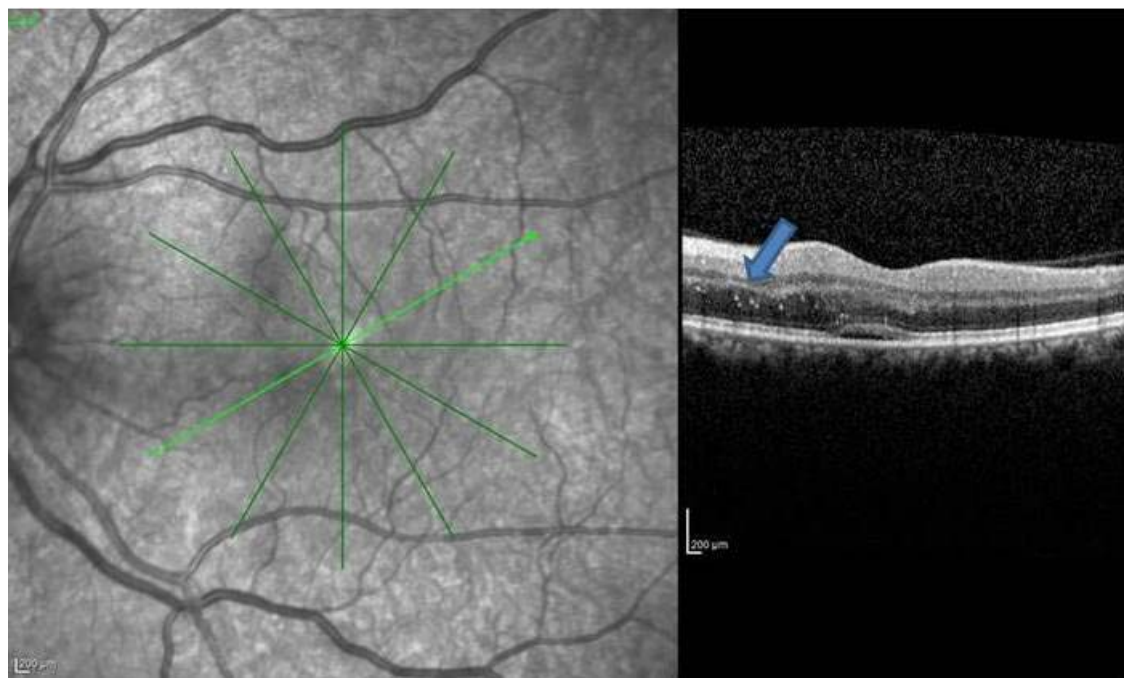

Fig. (4). Left eye, Swollen optic disc and hyperreflective dots (arrows).

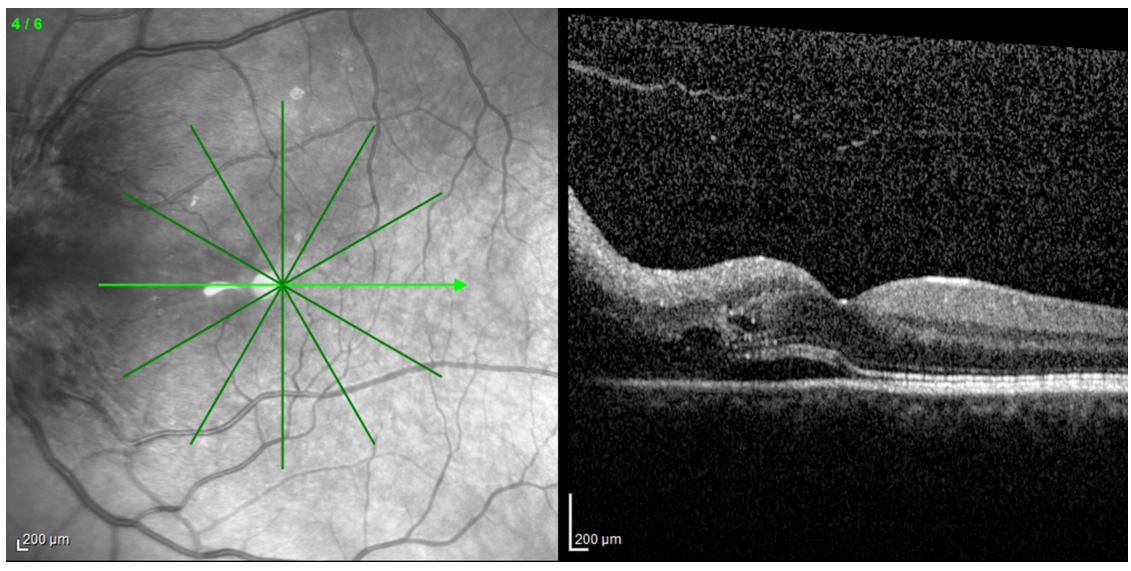

Fig. (5). Left eye, Swollen optic disc, subfoveal subretinal fluid extending to the papillomacular area with intraretinal fluid and hyperreflective dots. 


\section{DISCUSSION}

OCT technology particularly the spectral-domain type OCTs expands our knowledge in many retinal and optic nerve diseases $[5-7,10]$. Prior to OCT era the only well known macular change was the hard exudate accumulation forming a hemi or full star in eyes with acute acute NAION [11 - 14]. Usually hard exudates appear when the optic nerve swelling begins to resolve and therefore they are not present during the period of acute visual loss. In early 1980's Dreyer et al. [11] carried out a study in 27 eyes of 27 patients with neuroretinitis and macular star. In only three of them the diagnosis was acute NAION. Miller and Arnold [14] argued that a partial or complete macular star pattern of hard exudates should urge the clinician to seek out for other causes such as neuroretinitis. Recently Galvez-Ruiz [7] described 12 cases of which 11 were diabetic with macular hemistar formation and acute NAION. They argued that the lower frequency of macular hard exudates in association with acute NAION in the scientific literature might be due not only that this was an uncommon condition but also that it could easily be overlooked if a second fundus examination was not performed during the course. In the current study, we could observe macular hard exudates in only one eye as we took into account only the initial examination. It is likely that a longitudinal examination might have revealed more than one case.

Subretinal fluid accumulation in eyes with acute NAION could be noticed only after the incorporation of OCT technology into the ophthalmic practise. Hedges et al. [6] looked for the presence of subretinal fluid with the Stratus OCT in the wake of acute NAION. Seventy six patients from two institutions underwent macular OCT examination within four weeks of developing unilateral visual loss. Eight patients (10\%) had apparent subretinal fluid extending into the subretinal space. Visual acuity improved in five of these eight patients as the subretinal fluid resolved. Of the 44 patients from one of the two institutions (New England Eye Center), nine had only peripapillary fluid and 19 had both peripapillary and subretinal fluid extending toward but not involving the macula. Thereby the authors argued that some degree of subretinal fluid accumulation seems to occur in more than half of the patients with acute NAION and suggested that subretinal fluid might contribute to some of the visual loss associated with acute NAION and that resolution of the fluid might account for the visual improvement that often occurred during the course. Tawse et al. [15] in their comprehensive review on OCT changes observed in optic nerve diseases suggested that subfoveal subretinal fluid occurred in about $15 \%$ of patients with acute NAION and speculated about the source of the subretinal fluid. According to them subretinal fluid did not likely arise directly from the choroid or retinal vessels as fluorescein angiogram did not show any evidence of leakage. There might be a disruption of the glial tissue that comprise the intermediate tissue of Kuhnt similar to what occurs in papilledema. Thereby subretinal fluid likely escapes from the peripapillary choroid into the subretinal space and tracks into the macula. In our study group, some subretinal fluid presence was noted in $34.9 \%$ of the eyes.

We previously suggested that one of the reasons to administer intravitreal antiVEGF agents in acute NAION is the presence of subretinal fluid, as anti VEGF agents may theoratically alleviate the subretinal fluid and thereby help the improvement of visual acuity [16 - 18]. However, the use of intravitreal anti VEGF's is highly controversial in eyes with a NAION and Rootman et al. [19] found no difference between injection (1,25 mg bevacizumab) and control group regarding the change in visual field, visual acuity and retinal nerve fiber layer thickness. Even two of their 17 treated eyes experienced a second acute NAION episode after the injections.

To the best of our knowledge, presence of hyperreflective dots has not been reported in eyes with acute NAION with the help of OCT. Hyperreflective dots could be the precursor of hard exudates or more commonly believed to be the activated microglial cells [20 - 22]. In our study group, OCT scans passing through the foveola exhibited 10 or more hyperreflective dots in $10(15 \%)$ of the study eyes. Further studies may shed a light on the implication of the presence of intraretinal hyperreflective dots in acute NAION.

In light of our study and the literature review, we feel that macular OCT can be a part of the routine neuroophthalmological examination of patients with acute NAION not only to show the NAION related changes such as the subretinal fluid accumulation but also to identify many other coexistent macular abnormalities.

\section{ETHICS APPROVAL AND CONSENT TO PARTICIPATE}

Not applicable.

\section{HUMAN AND ANIMAL RIGHTS}

No Animals/Humans were used for studies that are base of this research. 


\section{CONSENT FOR PUBLICATION}

Not applicable.

\section{CONFLICT OF INTEREST}

The authors confirm that this article content has no conflict of interest.

\section{ACKNOWLEDGEMENTS}

Declared none.

\section{REFERENCES}

[1] Hayreh SS. Anterior ischaemic optic neuropathy. I. Terminology and pathogenesis. Br J Ophthalmol 1974; 58(12): 955-63. [http://dx.doi.org/10.1136/bjo.58.12.955] [PMID: 4376415]

[2] İbrahimov E, Selver OB, Ozturk AT, et al. Evaluation of retinal nerve fiber layer thickness in swollen optic disc. Ret-Vit 2010; 18: 154-8.

[3] Liu T, Bi H, Wang X, et al. Change of retinal nerve fiber layer thickness in patients with nonarteritic inflammatory anterior ischemic optic neuropathy. Neural Regen Res 2012; 7(35): 2778-83. [PMID: 25317127]

[4] Rebolleda G, Sánchez-Sánchez C, González-López JJ, Contreras I, Muñoz-Negrete FJ. Papillomacular bundle and inner retinal thicknesses correlate with visual acuity in nonarteritic anterior ischemic optic neuropathy. Invest Ophthalmol Vis Sci 2015; 56(2): 682-92. [http://dx.doi.org/10.1167/iovs.14-15314] [PMID: 25587057]

[5] Papchenko T, Grainger BT, Savino PJ, Gamble GD, Danesh-Meyer HV. Macular thickness predictive of visual field sensitivity in ischaemic optic neuropathy. Acta Ophthalmol 2012; 90(6): e463-9. [http://dx.doi.org/10.1111/j.1755-3768.2012.02467.x] [PMID: 22690753]

[6] Hedges TR III, Vuong LN, Gonzalez-Garcia AO, Mendoza-Santiesteban CE, Amaro-Quierza ML. Subretinal fluid from anterior ischemic optic neuropathy demonstrated by optical coherence tomography. Arch Ophthalmol 2008; 126(6): 812-5. [http://dx.doi.org/10.1001/archopht.126.6.812] [PMID: 18541844]

[7] Galvez-Ruiz A. Macular star formation in diabetic patients with non-arteritic anterior ischemic optic neuropathy (NA-AION). Saudi J Ophthalmol 2015; 29(1): 71-5.

[http://dx.doi.org/10.1016/j.sjopt.2014.09.002] [PMID: 25859144]

[8] Characteristics of patients with nonarteritic anterior ischemic optic neuropathy eligible for the Ischemic optic neuropathy decompression trial. Arch Ophthalmol 1996; 114(11): 1366-74. [http://dx.doi.org/10.1001/archopht.1996.01100140566007] [PMID: 8906027]

[9] Coscas G, De Benedetto U, Coscas F, et al. Hyperreflective dots: a new spectral-domain optical coherence tomography entity for follow-up and prognosis in exudative age-related macular degeneration. Ophthalmologica 2013; 229(1): 32-7. [http://dx.doi.org/10.1159/000342159] [PMID: 23006969]

[10] Larrea BA, Iztueta MG, Indart LM, Alday NM. Early axonal damage detection by ganglion cell complex analysis with optical coherence tomography in nonarteritic anterior ischaemic optic neuropathy. Graefes Arch Clin Exp Ophthalmol 2014; 252(11): $1839-46$. [http://dx.doi.org/10.1007/s00417-014-2697-0] [PMID: 25107540]

[11] Dreyer RF, Hopen G, Gass JD, Smith JL. Lebers idiopathic stellate neuroretinitis. Arch Ophthalmol 1984; $102(8): 1140-5$. [http://dx.doi.org/10.1001/archopht.1984.01040030918013] [PMID: 6466174]

[12] Soylev MF, Saatci O, Memisoglu B. Non-arteritic ischemic optic neuropathy and macula. Congress of Turkish Ophthalmology,Congress book. $890-91$

[13] Wang AG, Liu JH, Lin CL, Yen MY. Macular Star in optic neuropathy. Ann Ophthalmol 1995; 27: $107-12$.

[14] Miller NR, Arnold AC. Current concepts in the diagnosis, pathogenesis and management of nonarteritic anterior ischaemic optic neuropathy. Eye (Lond) 2015; 29(1): 65-79. [http://dx.doi.org/10.1038/eye.2014.144] [PMID: 24993324]

[15] Tawse KL, Hedges TR III, Gobuty M, Mendoza-Santiesteban C. Optical coherence tomography shows retinal abnormalities associated with optic nerve disease. Br J Ophthalmol 2014; 98(Suppl. 2): ii30-3.

[http://dx.doi.org/10.1136/bjophthalmol-2013-304301] [PMID: 24627251]

[16] Bajin MS, Selver OB, Taskin O, Yaman A, Saatci AO. Single intravitreal ranibizumab injection in eyes with acute non-arteritic anterior ischaemic optic neuropathy. Clin Exp Optom 2011; 94(4): 367-70. [http://dx.doi.org/10.1111/j.1444-0938.2010.00570.x] [PMID: 21255078]

[17] Saatci AO, Taskin O, Selver OB, Yaman A, Bajin MS. Efficacy of intravitreal ranibizumab injection in acute nonarteritic ischemic optic neuropathy: a long-term follow up. Open Ophthalmol J 2013; 7(7): 58-62. [http://dx.doi.org/10.2174/1874364101307010058] [PMID: 24133556]

[18] Ayhan Z, Kocaoğlu G, Yaman A, et al. Single intravitreal aflibercept injection for unilateral acute nonarteritic ischemic optic neuropathy. 
Case Rep Ophthalmol Med 2015; 2015: 783241.

[http://dx.doi.org/10.1155/2015/783241]

[19] Rootman DB, Gill HS, Margolin EA. Intravitreal bevacizumab for the treatment of nonarteritic anterior ischemic optic neuropathy: a prospective trial. Eye (Lond) 2013; 27(4): 538-44. [http://dx.doi.org/10.1038/eye.2012.296] [PMID: 23370417]

[20] Bolz M, Schmidt-Erfurth U, Deak G, Mylonas G, Kriechbaum K, Scholda C. Optical coherence tomographic hyperreflective foci: a morphologic sign of lipid extravasation in diabetic macular edema. Ophthalmology 2009; 116(5): 914-20. [http://dx.doi.org/10.1016/j.ophtha.2008.12.039] [PMID: 19410950]

[21] Deák GG, Bolz M, Kriechbaum K, et al. Effect of retinal photocoagulation on intraretinal lipid exudates in diabetic macular edema documented by optical coherence tomography. Ophthalmology 2010; 117(4): 773-9. [http://dx.doi.org/10.1016/j.ophtha.2009.09.027] [PMID: 20079541]

[22] Gelman SK, Freund KB, Shah VP, Sarraf D. The pearl necklace sign: a novel spectral domain optical coherence tomography finding in exudative macular disease. Retina 2014; 34(10): 2088-95. [http://dx.doi.org/10.1097/IAE.0000000000000207] [PMID: 25020214]

(C) Donmez et al.; Licensee Bentham Open

This is an open access article licensed under the terms of the Creative Commons Attribution-Non-Commercial 4.0 International Public License (CC BY-NC 4.0) (https://creativecommons.org/licenses/by-nc/4.0/legalcode), which permits unrestricted, non-commercial use, distribution and reproduction in any medium, provided the work is properly cited. 